\title{
Crossover study of proportional assist versus assist control ventilation
}

\author{
Prashanth Bhat, ${ }^{1}$ Deena-Shefali Patel, ${ }^{1}$ Simon Hannam, ${ }^{1}$ Gerrard F Rafferty, ${ }^{1}$ \\ Janet L Peacock, ${ }^{2,3}$ Anthony D Milner, ${ }^{1}$ Anne Greenough ${ }^{1,3}$
}

${ }^{1}$ Division of Asthma, Allergy and Lung Biology, MRC Centre for Allergic Mechanisms in Asthma, King's College London, London, UK ${ }^{2}$ Division of Health and Social Care Research, King's College London, London, UK

${ }^{3}$ NIHR Biomedical Research Centre at Guy's and St Thomas' NHS Foundation Trust and King's College London, London, UK

\section{Correspondence to}

Professor Anne Greenough, NIHR Biomedical Research

Centre at Guy's and St Thomas' NHS Foundation Trust and King's College London, NICU, 4th Floor Golden Jubilee Wing, King's College Hospital, Denmark Hill, London SE5 9RS, UK;

anne.greenough@kcl.ac.uk

Received 10 December 2013 Revised 6 May 2014 Accepted 8 May 2014 Published Online First 28 May 2014

\section{SLinked}

- http://dx.doi.org/10.1136/ fetalneonatal-2014-306669

\section{CrossMark}

To cite: Bhat $P$, Patel D-S, Hannam S, et al. Arch Dis Child Fetal Neonatal Ed 2015;100:F35-F38.

\section{ABSTRACT}

Objective To test the hypothesis that in very

prematurely born infants remaining ventilated beyond the first week, proportional assist ventilation (PAV) compared with assist control ventilation (ACV) would be associated with reduced work of breathing, increased respiratory muscle strength and less ventilator-infant asynchrony which would be associated with improved oxygenation.

Design Randomised crossover study.

Setting Tertiary neonatal unit.

Patients 12 infants with a median gestational age of 25 (range 24-26) weeks were studied at a median of 43 (range 8-86) days.

Interventions Infants were studied for $1 \mathrm{~h}$ each on PAV and ACV in random order.

Main outcome measures At the end of each hour, the work of breathing (assessed by measuring the diaphragmatic pressure time product), thoracoabdominal asynchrony and respiratory muscle strength (maximal inspiratory pressure, maximal expiratory pressure (Pemax) and maximal transdiaphragmatic pressure (Pdimax)) were assessed. Blood gas analysis was performed and the oxygenation index (OI) calculated.

Results After $1 \mathrm{~h}$ on PAV compared with $1 \mathrm{~h}$ on ACV, the median OI (5.55 (range 5-11) vs 10.10 (range 7-16), $p=0.002$ ) and PTP levels were lower (217 (range 59-556) $\mathrm{cm} \mathrm{H}_{2} \mathrm{O}$.s/min vs 309 (range 55-544) $\mathrm{cm} \mathrm{H}_{2} \mathrm{O}$. s/min, $p=0.005)$, while Pdimax (44.26 (range 21-66) $\mathrm{cm} \mathrm{H}_{2} \mathrm{O}$ vs 37.9 (range 19-45) $\mathrm{cm} \mathrm{H}_{2} \mathrm{O}, \mathrm{p}=0.002$ ) and Pemax (25.6 (range 6.5-42) cm $\mathrm{H}_{2} \mathrm{O}$ vs 15.9 (range $3-35) \mathrm{cm} \mathrm{H}_{2} \mathrm{O}$ levels $\mathrm{p}=0.010$ ) were higher.

Conclusions These results suggest that PAV compared with ACV may have physiological advantages for prematurely born infants who remain ventilated after the first week after birth.

\section{INTRODUCTION}

The survival of very prematurely born infants has improved considerably over the last decades, but many survive with bronchopulmonary dysplasia (BPD) and suffer chronic respiratory morbidity. As a consequence, new modes of ventilation have been developed with the hope that their use might improve respiratory outcomes. One such mode is proportional assist ventilation (PAV). During PAV, the applied pressure is servo controlled, based on continuous input from the infant throughout each spontaneous breath. In addition, the ventilator can provide inflation pressure in phase with the tidal volume change in order to reduce the compliance load (ie, the load due to the stiffness of infant's lungs) and in phase with the flow change to reduce the resistance load (ie, the load due airflow obstruction), termed elastic and resistive unloading,

\section{What is already known on this topic}

During proportional assist ventilation (PAV), the applied pressure is servo controlled throughout each spontaneous breath.

- Elastic and resistive 'unloading' can compensate for the infant's abnormalities in lung mechanics.

\section{What this study adds}

- In prematurely born infants ventilated beyond 1 week of age, PAV versus assist control ventilation (ACV) was associated with a reduced work of breathing.

- After $1 \mathrm{~h}$ on PAV versus ACV, the oxygenation index was significantly lower.

- Respiratory muscle strength was higher after $1 \mathrm{~h}$ on PAV than ACV.

respectively. ${ }^{1}$ The clinician can set the level of unloading, which should potentially decrease the infant's work of breathing. Unloading might be particularly helpful in very prematurely born infants ventilated beyond the first week after birth, as such infants are at high risk of developing BPD and can have severe lung function abnormalities. In a randomised crossover comparison of PAV and patient triggered ventilation (assist control ventilation (ACV) or synchronised intermittent mandatory ventilation (SIMV)) which included 22 ventilator dependent infants with evolving BPD, gas exchange was successfully maintained at significantly lower mean and peak pressures on $\mathrm{PAV}^{2}$ A limitation of that study was that two different ventilators (the Stephanie (Fritz Stephan GmbH) for PAV and the BabyLog 8000 (Draeger) for ACV and SIMV) were used which might have influenced the results. PAV has been shown to reduce thoracoabdominal asynchrony (TAA) compared with support by continuous positive airways pressure in prematurely born infants. ${ }^{3}$ Reduction in TAA might improve oxygenation. Lower levels of asynchrony might also reduce the likelihood of respiratory muscle fatigue and infants then might have better respiratory muscle strength on PAV. The aim of our study was, therefore, to test the hypothesis that the work of breathing and ventilator-infant asynchrony would be lower and respiratory muscle strength would be 
better and hence there would be improved oxygenation after a $1 \mathrm{~h}$ period on PAV compared with after a $1 \mathrm{~h}$ period on ACV in prematurely born infants remaining ventilator dependent after the first week after birth.

\section{METHODS}

Prematurely born infants remaining ventilated after the first week after birth were eligible for entry into this study if they were being supported by ACV. Infants were entered into the study if their parents gave informed written consent. The study was approved by the South East London Research Ethics Committee and King's College Hospital Research Ethics Committee.

Infants at King's College Hospital are routinely supported by the SLE 5000. For the purposes of this study, the infants were transferred from the SLE 5000 ventilator to ACV on the Stephanie ventilator using the same ventilator settings (baseline). All infants as per the unit's routine policy were ventilated via shouldered endotracheal tubes which have been shown to have minimal or no leaks. ${ }^{4}$ One hour was allowed for stabilisation of the infant on the Stephanie ventilator. A blood gas analysis was then performed and the baseline ventilator settings were noted. During the stabilisation period, compliance and resistance settings were noted every $10 \mathrm{~min}$ when the infant was not obviously fighting the ventilator and the six results meaned. The infant was then randomised to receive first either PAV or ACV mode each for $1 \mathrm{~h}$ and for the second hour the alternative mode. During ACV, the peak inspiratory pressure (PIP), positive end expiratory pressure (PEEP) and the inflation time were kept the same as at baseline. The backup rate was set at 40 breaths per minute. During PAV, the maximum PIP was set at $5 \mathrm{~cm} \mathrm{H}_{2} \mathrm{O}$ above the PIP on ACV, as recommended by Schulze et al. ${ }^{2}$ The PEEP level during PAV was the same as at baseline and the PEEP and the inflation time during back up ventilation was the same as at baseline. Whenever cessation of spontaneous breathing occurred for more than $5 \mathrm{~s}$ during PAV, mandatory backup inflations were automatically delivered by the ventilator until the infant made a spontaneous breath. Elastic unloading, which was used only during inspiration, was initially set at $75 \%$ of full unloading; full unloading was the level of unloading which increased the infant's compliance to the expected 'normal', that is, $2.0 \mathrm{~mL} / \mathrm{cm} \mathrm{H}_{2} \mathrm{O}$. If after $10 \mathrm{~min}$ the infant remained stable and no airway pressure waveform abnormalities were observed, the unloading was increased to $100 \%$. If airway pressure waveform abnormalities were then noted, ${ }^{5}$ the unloading was reduced back to $75 \%$. Although the infants currently studied were all ventilator dependent beyond 1 week after birth, their respiratory system resistances were not found, on average, to be very high; the median respiratory system resistance was 86.5 (range 85-174) $\mathrm{cm} \mathrm{H}_{2} \mathrm{O} / \mathrm{L} / \mathrm{s}$. We have previously demonstrated that the likelihood of oscillations appearing in the airway pressure waveform was greater when elastic unloading was used in a low compared with a high resistance model. ${ }^{5}$ In addition, in the in vitro model, ${ }^{5}$ oscillations in the airway pressure waveform appeared when the resistive unloading was greater than $100 \mathrm{~cm} \mathrm{H}_{2} \mathrm{O} / \mathrm{L} / \mathrm{s}$. Hence, in this study, we decided not to use resistive unloading.

During the last $5 \mathrm{~min}$ on each mode, the work of breathing, the level of asynchrony, respiratory muscle strength and blood gases were measured. The work of breathing was assessed by measurement of the transdiaphragmatic pressure time product (PTPdi). Transdiaphragmatic pressure (Pdi) was obtained from measurements of oesophageal (Poes) and gastric (Pgas) pressures, measured using a dual-pressure transducer tipped catheter and associated amplifier (Gaeltec, Dunvegan, UK). The two pressure transducers were $5 \mathrm{~cm}$ apart, with the lower transducer positioned $0.3 \mathrm{~cm}$ from the catheter tip. Correct positioning of the gastric transducer was confirmed by a positive pressure deflection during inspiration while the position of the oesophageal transducer was determined by comparing Poes and airway pressure during an occluded inspiratory effort. Agreement within $94 \%$ and 103\% indicated that the catheter was correctly located in the lower third of the oesophagus, and intrathoracic pressure could be reliably estimated. ${ }^{6} 7$ Airflow was measured using a pneumotachograph (Mercury F10L; GM Instruments, Kilwinning, UK) connected to a differential pressure transducer (MP45; Validyne Corporation, Northridge, California, USA). The pneumotachograph was positioned between the endotracheal tube and the ventilator manifold. Airway pressure was measured from a side port on the pneumotachograph using a second differential pressure transducer (MP45; Validyne Corporation). The signals from the flow and airway pressure transducers were amplified using a carrier amplifier (CD280; Validyne Corporation). The pressure and flow signals were recorded and displayed in real time on a computer (Dell Optiplex 170L) running an application written with Labview software (National Instruments, Austin, Texas, USA) with $100 \mathrm{~Hz}$ analogue-to-digital sampling (PCI-MIO-16XE-50, National Instruments).

Transdiaphragmatic pressure was calculated by the digital subtraction of Poes from Pgas by the acquisition software. The PTPdi was obtained by integration of Pdi with time for each breath and expressed per minute. The beginning and the end of the inspiratory phase of each breath were determined from the phase transition of the flow signal. The mean PTPdi was calculated from the first set of 20 consecutive breaths without artefact during the last 5 min of each hour on ACV and PAV modes.

Respiratory muscle strength was assessed by performing airway occlusions to obtain the maximum inspiratory (Pimax), maximum expiratory (Pemax) and maximum transdiaphragmatic (Pdimax) pressures. Airway occlusions were maintained for five to seven breaths and three sets of occlusions were performed. Sufficient time was allowed between occlusions for the infant to settle to quiet tidal breathing. The airway occlusion was discontinued if a pronounced desaturation or bradycardia occurred. A two-way non-breathing valve attached to the distal end of the pneumotachograph was used during when performing the occlusion. To assess Pimax and Pdimax, the inspiratory limb of the two-way valve was occluded during the preceding expiratory phase; the valve allowed expiration, but not inspiration. To assess Pemax, the expiratory limb of the two-way valve was occluded during the preceding inspiratory phase; the valve allowed inspiration, but not expiration. The maximum pressures achieved from the series of occlusions were recorded.

TAA was assessed by respiratory inductance plethysmography (Ambulatory Monitoring Inc, Ardsley, New York, USA). The rib cage band was placed at the level of the nipples and the abdominal band was placed midway between the bottom of the rib cage and the iliac crest. The signals were recorded and displayed in real time on a computer (Dell Optiplex 170L) running Spectra software (3.0.1.4) (Grove Medical, London, UK). From the recorded traces of the rib cage and abdominal wall motion, 10 consecutive artefact free breaths were selected and a Lissajous figure constructed. The phase angle $\phi$ was calculated as an index of TAA. ${ }^{8}$ A $0^{\circ}$ phase angle represents synchronous motion of the ribcage and abdomen while a $180^{\circ}$ phase angle represents completely out-of-phase or paradoxical motion between rib cage and abdomen. ${ }^{9}$ 
The number of desaturations (desaturation defined as an oxygen saturation less than $88 \%$ ) on each mode was noted. An arterial blood sample from an indwelling catheter was obtained at the end of each hour, the ventilatory settings were noted and the oxygenation index (OI) was calculated.

\section{Sample size}

The planned sample size was 18 infants to allow detection between the two ventilator modes of a difference equivalent to $0.7 \mathrm{SD}$ in the results of the physiological measurements with $80 \%$ power and two-sided significance of $5 \%$.

\section{Analysis}

The differences in the results between the two modes were analysed with Wilcoxon signed rank test using IBM SPPS statistical software, V.21 (IBM Corporation, USA).

\section{RESULTS}

Recruitment to the trial was stopped at 12 patients since it emerged at that point that the OI results were in favour of PAV for all 12 patients. The decision was taken by the clinical team and the trial statistician in the knowledge that the probability of $12 / 12$ results in the same direction (here favouring PAV), if both modes were in fact equally effective, was extremely small at $0.0002\left(0.5^{12}\right)$. In addition, although there were no apparent adverse effects, certain of the physiological measurements are invasive and/or require airway occlusions. Hence, it was unanimously agreed that it was both inappropriate and unnecessary to continue the trial further since the hypothesis had been conclusively answered.

The attained sample of 12 infants allowed the detection of a difference of 0.9 SDs with $80 \%$ power and two-sided significance of 5\%. The 12 infants (seven boys) had a median gestational age of 25 (range 24-26) weeks, birth weight of 721 (range 535-930) $\mathrm{g}$ and baseline inspired oxygen fraction $\left(\mathrm{FiO}_{2}\right)$ of 0.50 (range $0.45-0.70$ ) and were studied at a median age of
43 (range 8-86) days, when they had a mean weight of 990 (range 598-1530) g. Their median baseline compliance was 0.6 (range 0.3-0.9) $\mathrm{mL} / \mathrm{cm} \mathrm{H}_{2} \mathrm{O}$ (median 0.6, range $0.4-1.0 \mathrm{~mL} /$ $\mathrm{cm} \mathrm{H}_{2} \mathrm{O} / \mathrm{kg}$ ). No wave form abnormalities were noted in any of the 12 infants when studied at 75\% elastic unloading. At $100 \%$ unloading two infants had desaturations, although no waveform abnormalities. They were, therefore, returned to $75 \%$ of unloading at which level they remained throughout the rest of the PAV study period without waveform abnormalities appearing or further desaturations.

Five of the 12 infants were studied first on PAV. Overall, after $1 \mathrm{~h}$ on PAV, the median mean airway pressure was significantly lower than after $1 \mathrm{~h}$ on $\mathrm{ACV}$ (8.4 (range 7-9) $\mathrm{cm} \mathrm{H}_{2} \mathrm{O}$ vs 9.1 (range 7-11) $\mathrm{cm} \mathrm{H}_{2} \mathrm{O}$, respectively, $\mathrm{p}=0.028$ ). In addition, on $\mathrm{PAV}$ the peak inflation pressures (17 (range 13-20) $\mathrm{cm} \mathrm{H}_{2} \mathrm{O}$ vs 18 (range 14-20) $\mathrm{cm} \mathrm{H}_{2} \mathrm{O}, \mathrm{p}=0.036$ ) were significantly lower (figure 1).

After $1 \mathrm{~h}$ on PAV compared with $1 \mathrm{~h}$ on ACV, the PTP levels were lower $(p=0.005)$ and Pdimax levels $(p=0.002)$ and Pemax levels $(p=0.010)$ were higher (table 1$)$. The median OI following $1 \mathrm{~h}$ on PAV was significantly lower than that following $1 \mathrm{~h}$ on ACV $(p=0.002)$. There were no significant differences in the $\mathrm{PaCO}_{2}$ levels between the two modes $(p=0.814)$ and the number of desaturation episodes was similar $(p=0.20)$.

\section{DISCUSSION}

We have demonstrated that PAV compared with ACV in prematurely born infants ventilated beyond the first week after birth resulted in a reduced work of breathing and a lower OI. The lower OI is in keeping with the findings of Schulze and colleagues $^{2}$ that despite a reduced mean airway pressure on PAV compared with ACV/SIMV, the inspired oxygen level and pulse oximetry readings were not significantly different on the two modes in very prematurely born infants (mean gestational age 25.6 weeks) with evolving chronic lung disease. In addition, in prematurely born infants with acute respiratory distress (birth
Figure 1 Volume, airway and oesophageal pressures on assist control ventilation (ACV) and proportional assist ventilation (PAV). The airway pressure varies according to oesophageal pressure during PAV, but not ACV.

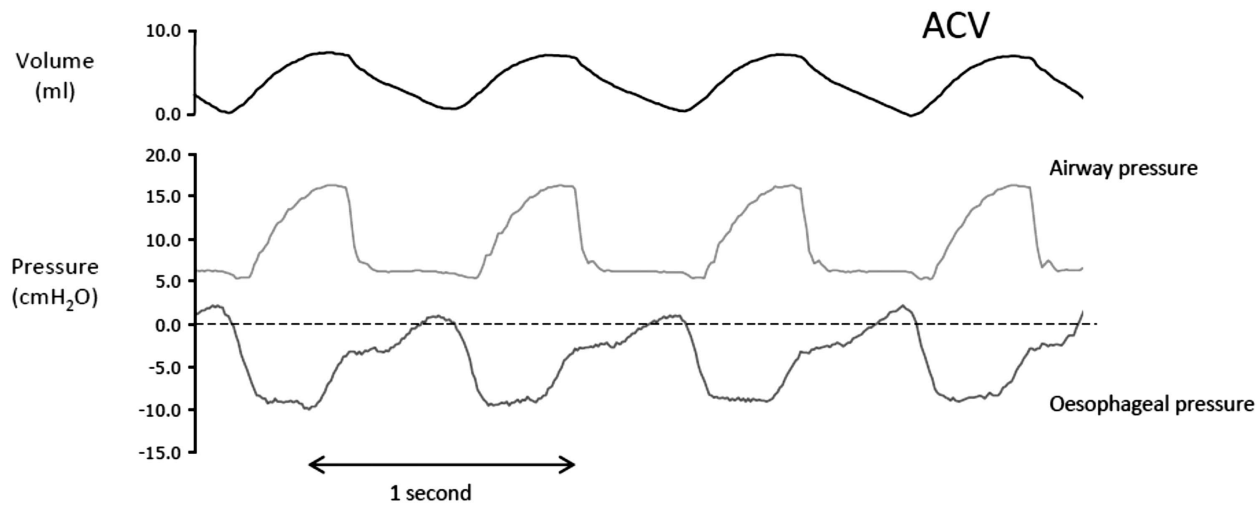

Volume

(ml)
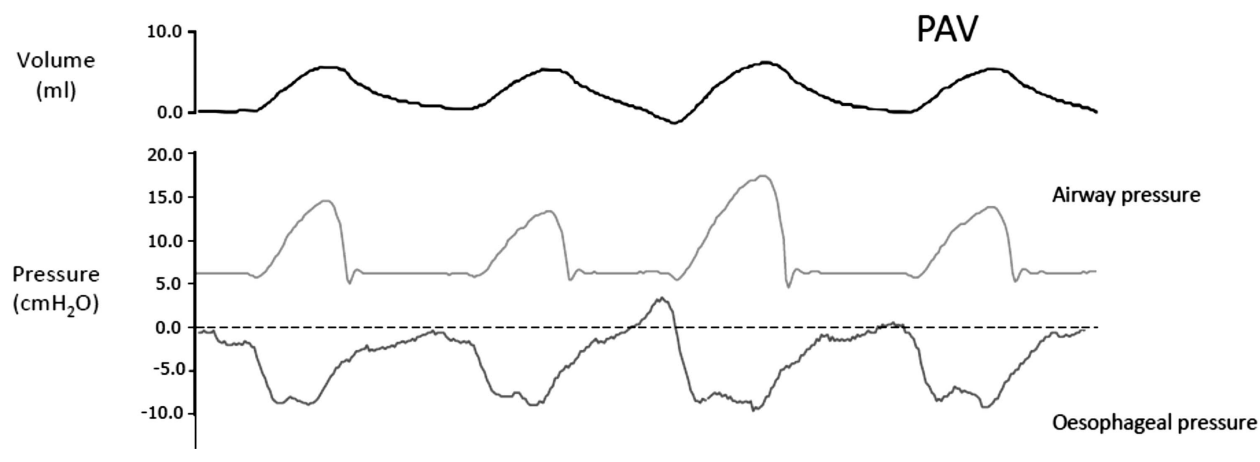
Table 1 Comparison of airway pressures, physiological outcomes and blood gas exchange by ventilator mode

\begin{tabular}{lccl}
\hline & PAV & ACV & p Value \\
\hline Mean airway pressure $\left(\mathrm{cm} \mathrm{H}_{2} \mathrm{O}\right)$ & $8.4(7.1-9.0)$ & $9.1(7.1-11.0)$ & 0.028 \\
Peak inflation pressure $\left(\mathrm{cm} \mathrm{H}_{2} \mathrm{O}\right)$ & $17(13-20)$ & $18(14-20)$ & 0.036 \\
PTPdi $\left(\mathrm{cm} \mathrm{H}_{2} \mathrm{O} . \mathrm{s} / \mathrm{min}\right)$ & $217(60-556)$ & $309(55-544)$ & 0.005 \\
Pimax $\left(\mathrm{cm} \mathrm{H}_{2} \mathrm{O}\right)$ & $21.9(11.2-37.3)$ & $23.6(13.6-38.6)$ & 0.182 \\
Pemax $\left(\mathrm{cm} \mathrm{H}_{2} \mathrm{O}\right)$ & $25.7(6.5-42.7)$ & $15.9(3.0-35.7)$ & 0.010 \\
Pdimax $\left(\mathrm{cm} \mathrm{H}_{2} \mathrm{O}\right)$ & $44.3(21.3-66.4)$ & $37.9(19.5-45.2)$ & 0.002 \\
TAA (degrees) & $1.2(0.4-3.5)$ & $1.9(1.2-3.3)$ & 0.050 \\
Respiratory rate (bpm) & $54(40-66)$ & $57(46-74)$ & 0.025 \\
Expiratory tidal volume $(\mathrm{mL} / \mathrm{kg})$ & $6.8(3.7-7.4)$ & $7.2(2.7-7.8)$ & 0.182 \\
$\mathrm{SaO}_{2}$ (\%) & $96(93-98)$ & $93(92-98)$ & 0.021 \\
$\mathrm{FiO}_{2}$ & $0.40(0.21-0.50)$ & $0.50(0.30-0.60)$ & 0.005 \\
PaO $_{2}$ (kpa) & $7.2(4.4-13.2)$ & $6.1(3.9-11.7)$ & 0.158 \\
Oxygenation index $_{\text {PaCO }}$ (kpa) & $5.6(5.0-10.7)$ & $10.1(7-16.1)$ & 0.002 \\
Desaturation episodes $(\mathrm{n})$ & $7.6(5.7-10.0)$ & $7.6(5.7-12.1)$ & 0.814 \\
\hline
\end{tabular}

The results are expressed as the median (range).

ACV, assist control ventilation; PAV, proportional assist ventilation; TAA, thoracoabdominal asynchrony.

weights between 600 and $1200 \mathrm{~g}$ ) on 45 -min epochs on PAV compared with 45-min epochs on ACV or intermittent mandatory ventilation, similar arterial oxygenation was maintained despite lower airway and transpulmonary pressures during PAV. ${ }^{10}$ The lower mean airway pressure and lower OI we have demonstrated on PAV likely reflect that during PAV the applied pressure is servo controlled throughout each spontaneous breath, whereas during ACV, synchronisation of inflation is only at the beginning of inspiration. In addition, the lower OI might also reflect the reduced level of asynchrony during PAV, which just failed to reach statistical significance $(\mathrm{p}=0.05)$.

High airway pressures and airway pressure oscillations have been demonstrated when excessive amounts of elastic and resistive unloading are used. ${ }^{11}$ High airway pressures can be prevented by the use of a set limit on the maximum peak inflation pressure, provided care is taken to ensure this does not result in very short inflation times. ${ }^{12}$ In this study, a maximum peak inflation pressure was set as has been recommended ${ }^{2}$ and no airway pressure waveform abnormalities were experienced despite using up to $100 \%$ elastic unloading. Our results may also reflect we used only elastic unloading and not resistive unloading. The compliance used to determine the amount of unloading was taken from the ventilator display when the infants were supported by ACV during the stabilisation period. As they were able to make spontaneous efforts, it is possible the ventilator display gave an overestimate of compliance and we were not fully unloading them.

There are strengths and some limitations of our study. The same ventilator was used in both arms of the study and hence the significant differences we demonstrated reflected differences in ventilator mode rather than ventilator performance. A range of physiological assessments were made as well as blood gas analysis. The majority of the results favoured the use of PAV. Despite infants being only studied for $1 \mathrm{~h}$ on each mode, we demonstrated significant differences in the results obtained on the two modes. We did not observe any significant difference in the number of desaturations between the two modes, but we did not record the duration of desaturations, which were significantly longer on PAV in a previous study. ${ }^{2}$ In that study, ${ }^{2}$ however, all the infants had a previous history of frequent apnoeas and arterial oxygen desaturations. In addition, 'a lag time' of $10 \mathrm{~s}$ was used during which the ventilator software identified cessation of breathing, ${ }^{2}$ whereas we used a lag time of $5 \mathrm{~s}$.

In conclusion, we have demonstrated that $1 \mathrm{~h}$ on PAV compared with $1 \mathrm{~h}$ on ACV results in a significant improvement in the $\mathrm{OI}$ and a reduction in the work of breathing.

Contributors $A G, A D M, P B$ and DSP designed the study. PB undertook all the assessments, supported by GFR and SH. JLP advised on the analysis. All authors were involved in the production of the manuscript.

Funding PB was supported by the Charles Wolfson Charitable Trust. The research was supported by the National Institute for Health Research (NIHR) Biomedical Research Centre based at Guy's and St Thomas' NHS Foundation Trust and King's College London. The views expressed are those of the authors and not necessarily those of the NHS, the NIHR or the Department of Health. AG is an NIHR Senior Investigator.

Competing interests $A G$ has held grants from various ventilator manufacturers; $A G$ and ADM have received honoraria for giving lectures and advising various ventilator manufacturers. SH has received sponsorship for postgraduate courses from ventilator manufacturers.

Ethics approval South East London Research Ethics Committee and King's College Hospital Research Ethics Committee.

Provenance and peer review Not commissioned; externally peer reviewed.

Data sharing statement No additional data available.

\section{REFERENCES}

1 Schulze A. Respiratory mechanical unloading and proportional assist ventilation in infants. Acta Paediatr Supp/ 2002;437:19-22.

2 Schulze A, Rieger-Fackeldey E, Gerhardt T, et al. Randomized crossover comparison of proportional assist ventilation and patient-triggered ventilation in extremely low birth weight infants with evolving chronic lung disease. Neonatology 2007;92:1-7.

3 Musante G, Schulze A, Gerhardt T, et al. Proportional assist ventilation decreases thoracoabdominal asynchrony and chest wall distortion in preterm infants. Pediatr Res 2001;49:175-80.

4 Hird M, Greenough A, Gamsu HR. Gas trapping during high frequency positive pressure ventilation using conventional ventilators. Early Hum Dev 1990;22:51-6.

5 Patel DS, Rafferty GF, Hannam S, et al. In vitro assessment of proportional assist ventilation. Arch Dis Child Fetal Neonatal Ed 2010;95:F331-7.

6 Beardsmore CS, Helms P, Stocks J, et al. Improved oesophageal balloon technique for use in infants. J Appl Physiol 1980;49:735-42.

7 Baydur A, Behrakis PK, Zin WA, et al. A simple method for assessing the validity of the oesophageal balloon technique. Am Rev Respir Dis 1982;126:788-91.

8 Agostoni E, Mognoni P. Deformation of the chest wall during breathing efforts. J Appl Physiol 1966;21:1827-32.

9 Allen JL, Wolfson MR, McDowell K, et al. Thoracoabdominal Asynchrony in infants with airflow obstruction. Am Rev Respir Dis 1990;141:337-42.

10 Schulze A, Gerhardt T, Musante G, et al. Proportional assist ventilation in low birth weight infants with acute respiratory disease: a comparison to assist/control and conventional mechanical ventilation. J Pediatr 1999;135:339-44.

11 Schulze A, Rich W, Schellenberg L, et al. Effects of different gain settings during assisted mechanical ventilation using respiratory unloading in rabbits. Pediatr Res 1998;44:132-8

12 Leipälä JA, Iwasaki $S$, Lee $S$, et al. Compliance and resistance levels and unloading in proportional assist ventilation. Physiol Meas 2005;26:281-92. 